\title{
MONITORING CROP GROWTH STATUS BASED ON OPTICAL SENSOR
}

\author{
Di Cui ${ }^{1}$, Minzan $\mathrm{Li}^{1}$, Yan Zhu ${ }^{2}$, Weixing Cao ${ }^{2}$, Xijie Zhang ${ }^{1}$ \\ ${ }^{1}$ Key Laboratory of Modern Precision Agriculture System Integration Research, Ministry of \\ Education, China Agricultural University, Beijing 100083, China Corresponding author, \\ Email:limz@cau.edu.cn \\ ${ }^{2}$ Key Laboratory of Crop Growth Regulation; Ministry of Agriculture, Nanjing Agricultural \\ University, Nanjing 210095, China
}

Abstract: In order to detect the growth status and predict the yield of the crop, crop growth monitor measuring nitrogen content in the plant is developed based on optical principle. The monitor measures the spectral reflectance of the plant canopy at the $610 \mathrm{~nm}$ and $1220 \mathrm{~nm}$ wavebands, and then calculates the nitrogen content in the plant with the measured data. The field test was carried out to evaluate performance of the monitor. A portable multi-spectral radiometer named Crop Scan was used to measure the reflectance as a reference instrument. The result shows that the leaf reflectance measured by the monitor has a close linear correlation with that measured by Crop Scan at the $610 \mathrm{~nm}$ waveband $(\mathrm{R} 2=0.7604)$, but the correlation between them is needed to be improved at the $1220 \mathrm{~nm}$ waveband. The hardware and the software of the monitor are also explained in detail. It is still need to be improved to satisfy the demand of ground-based remote sensing in precision farming.

Keywords: nitrogen content; crop growth; ground-based remote sensing; precision agriculture

\section{INTRODUCTION}

Nitrogen content of the crop is an important index, which can be used to evaluate the growth status and predict the yield and the quality of the crop. So it is necessary to real time detect and diagnose the nitrogen status of the 
crop. Nitrogen fertilizer has a great effect on the reflectance of the light at visible band since the nitrogen fertilizer and the chlorophyll content are correlated (Stone, M. L. 1996). So the leaf nitrogen content can be estimated by analyzing the useful spectral features of crop canopy. Our object is to design an optical sensor to measure spectral reflectance of the plant canopy for determining $\mathrm{N}$ status in the plants.

\section{DEVELOPMENT OF A PORTABLE MONITOR FOR CROP GROWTH CONDITION}

\subsection{Structure of the portable Monitor}

Figure 1 shows the structure of the monitor. It was composed of the sensor and the controller. The sensor was designed with four channels representing different spectral bands. The channel 3 and channel 4 measured the sunlight, while the channel 1 and channel 2 measured the reflected light from the plant canopy. The angle of solar incidence can make the output of photodiode changing. In order to avoid this influence, the milky diffuse glass was used as the optical window of the channel 3 and channel 4 . The optical mirror was chose as the window of the channel 1 and channel 2. When using this detector to measure reflectance ratios, the sensor was lift on the top of the canopy and the output of the sensor was transmitted to the controller. Then the controller dealt with the output and saved the data.

Each channel consisted of an optical window, a washer, a filter, and a sensor. The channel 1 and the channel 3 had the same filters and sensors. The wavelength of the filter was $610 \mathrm{~nm}$ and the electric eye was made up of $\mathrm{Si}$. And the wavelength of the filter in the channel 2 and channel 4 was 1220 $\mathrm{nm}$. The photodiode in those was made up of InGaAs. The wavebands were determined based on the research report (Xue Lihong et al., 2004).

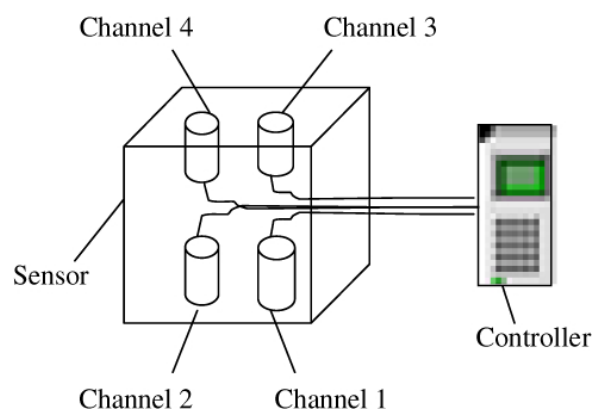

Figure 1. The structure of the portable crop growth monitor 


\subsection{Hardware Design}

Figure 2 shows the structure of electric circuits of the hardware. The photodiodes converted the optical signal into the electronic signal. The electronic signal went through an amplifier and an A/D transducer to be digitalized. The digital signal was calculated into chlorophyll content in the plants by the microcontroller, and the result was displayed on the LCD and stored in the Flash Disk through the USB port. The keyboard gave the indications to the microcontroller.

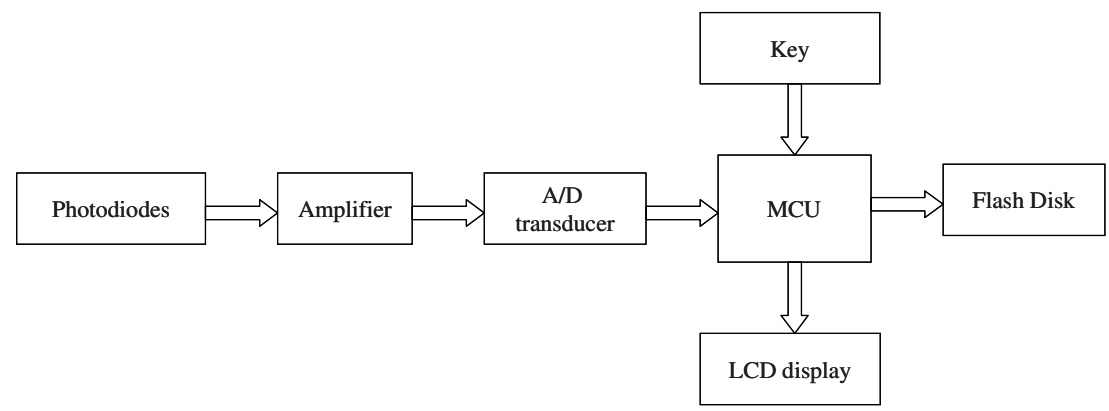

Figure 2. The Structure of electric circuits of the hardware

\section{PERFORMANCE TESTS AND RESULTS}

To evaluate performance of the monitor, we did field text in the wheat field of Nanjing Agricultural University on March 24. The weather was fine. There were 24 grids in the experiment field and the nitrogen content of each plat was different. The area of each grid was $5 \mathrm{~m} \times 5.5 \mathrm{~m}$. The wheat was $10 \mathrm{~cm}$ in height and didn't cover the ground. The soil between the two rows could be observed clearly. We used the monitor and Crop Scan to measure the reflectance of the wheat canopy. Each grid was measured five times along the two diagonals of each grid and the average was taken as the final result. At every sampling point, the samples were collected to measure the content nitrogen in the laboratory.

Figure 3 shows that the leaf reflectance measured by portable monitor has a close linear correlation with that measured by Crop Scan $(\mathrm{R} 2=0.7604)$ at the $610 \mathrm{~nm}$ wavelength. However, the correlation between those is needed to be improved at the $1220 \mathrm{~nm}$ wavelength (Figure 4). 


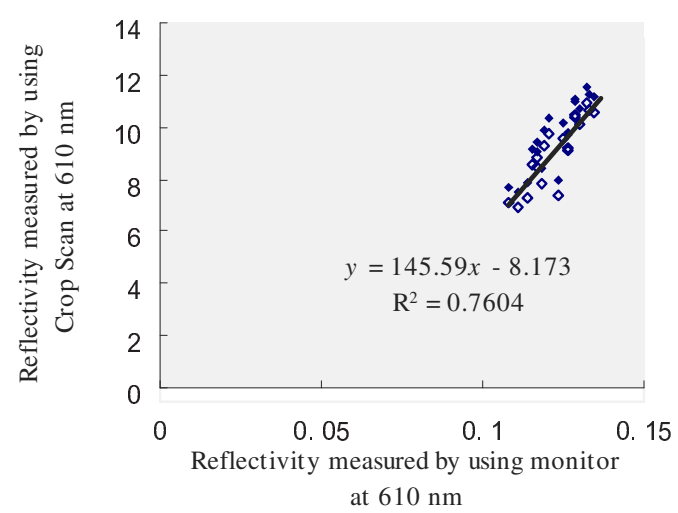

Figure 3. Relationship between Portable Monitor and Crop Scan at $610 \mathrm{~nm}$

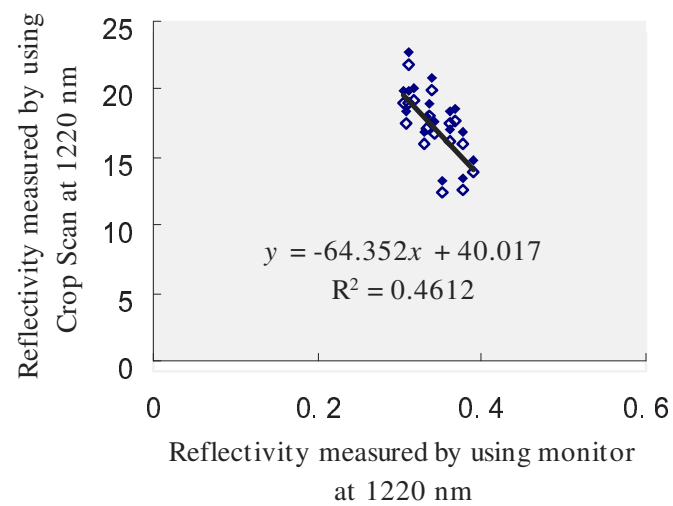

Figure 4. Relationships between Portable Monitor and Crop Scan at $1220 \mathrm{~nm}$

\section{CONCLUSION}

The portable crop growth monitor based on optical principle was developed and tested in the field. The Spectral reflectance was calculated using the monitor's outputs and showed a close correlation with the result measured by Crop Scan at $610 \mathrm{~nm}$ wavelength $(\mathrm{R} 2=0.7604)$, but not good at $1220 \mathrm{~nm}$ wavelength $(\mathrm{R} 2=0.4612)$. It may be caused by the height of wheat. In the future, more field tests will be performed to further test and to improve the device in order to make it satisfy the demand of precision farming. 


\section{ACKNOWLEDGEMENTS}

This study was supported by Key Program of Science and Technology, Ministry of Education (105013).

\section{REFERENCES}

Stone, M. L., J. B. Solie, W. R. Raun, R. W. Whitney, S. L. Taylor, and J. D. Ringer. Use of spectral radiance for correcting in-season fertilizer nitrogen deficiencies in winter wheat. Transactions of the ASAE, 1996, 39(5): 1623-1631

Xue Lihong, Cao Weixing, Luo Weihong, Zhang Xian. Correlation between leaf nitrogen status and canopy spectral characteristics in wheat. Acta Phytoecologica Sinica., 2004, 28 (2): $172-177$ 